\title{
RHYTHM AS ICONIC SELF REFERENCE: A BRIEF DEFINITION AND SOME POSSIBLE CONSEQUENCES
}

\section{Aldo Mazzucchelli}

\begin{abstract}
This paper's main goal is to show that rhythm can be defined and understood, in Peircean terminology, as iconic self-reference. This bears the immediate consequence that rhythm offers a way of -temporarily- escaping the process of unlimited semiosis (CP 2,303; 2,92). Within rhythm, iconic self-reference may create a recurrency of likenesses, suspending further reference to any third element external to rhythm. This paper will argue that some well known cognitive and emotional consequences of rhythm stem from this phenomenon, as semiotically defined here. In order to maintain consistency, I set a Peircean theoretical framework for this paper.
\end{abstract}

Keywords: rhythm, icon, self-reference, perceptual judgement, Charles S. Peirce.

\section{EL RITMO COMO AUTORREFERENCIA ICÓNICA: BREVE DEFINICIÓN Y ALGUNAS CONSECUENCIAS POSIBLES}

\section{Resumen}

El objetivo principal de este trabajo es mostrar que el ritmo puede ser definido, en términos peirceanos, según el concepto de auto-referencia icónica. Esto arroja la consecuencia inmediata de que el ritmo ofrece un modo peculiar de escape -siempre temporario- del proceso de semiosis ilimitada (CP 2,303; 2,92). Dentro del ritmo, la auto-referencialidad icónica puede crear una recurrencia de semejanzas, suspendiendo así ulteriores referencias a cualquier elemento externo al ritmo mismo. Este trabajo argumentará que algunas consecuencias emocionales y cognitivas bien conocidas del ritmo tienen origen en este fenómeno, definido aquí en términos semióticos. A efectos de mantener consistencia, la terminología teórica general empleada en este trabajo es la establecida en la obra de Charles S. Peirce.

Palabras clave: ritmo, ícono, auto-referencia, juicio perceptual, Charles S. Peirce.

* Este trabajo surge de dos instancias de investigación separadas en el tiempo. Su primer impulso se conecta con un seminario de trabajo independiente con el Dr. Hans U. Gumbrecht, en Stanford, en el año 2005. El germen de ideas surgido por entonces (que explica que el trabajo se haya desarrollado desde el comienzo en inglés) se actualiza en un breve proyecto de 3 meses ("Es posible pensar el ritmo como recurrencia icónica?"), que consistió en actualización bibliográfica y elaboración final del trabajo aquí presentado. Esta segunda instancia fue desarrollada y culminada durante el primer semestre del año 2014 en la Facultad de Comunicación y Diseño, Universidad ORT Uruguay. Agradezco a la Universidad ORT Uruguay, y el generoso apoyo del Sistema Nacional de Investigadores (SNI) de la Agencia Nacional de Investigación e Innovación (ANII), Uruguay.

Uruguayo. Investigador Asociado, Universidad ORT Uruguay, mzz017@gmail.com 


\section{Rhythm and Icons}

I depend on the premise that the iconical is the basis of representational. To acquire its representational character, an icon must be connected by likeness with some object distinct of the iconic object itself. This is the basis of the representational game. Any sign involved in an interpretation includes at least one of these icons guiding the process of reference (CP 2, 278) ${ }^{3}$. Now, if we are attempting to conceive the phenomenon of rhythm as something that suspends reference to anything external to rhythm itself, then it seems such phenomenon should be conceived as a kind of semiotic process which involves no representation, or a phenomenon where icons do not connect with anything external to rhythm itself. The first -and apparently, only- answer to this enigma would be an idea of 'pure perception, without interpretation'. But any perception is perception of something, and everything has features, qualities, to our senses. So, everything will be necessary converted by our mind in sign of something else, due to the likenesses which are automatically -or habitually- raised in our minds by our past experiences. This is a brief account of the well known process of unlimited semiosis, albeit, while considering rhythm, we would preventively restrict our considerations to the human mind only -but it is known that the process occurs outside of it as well, and there would be no problems to extend our conclusions to other beings.

The situation just described seems to force us to recognize that we as "the most imitative creature in the world" (Aristotle, p. 1448), are unable of escape the game of representation. 'Pure perception' will involve icons, which will lead us toward a new likeness, to ground another interpretation, and so forth. Our world appears to us as something infinitely interpretable, as a run of "infinite semiosis". Nevertheless, there could be a possibility of escaping of this nausea of infinite representation, and this possibility would be the alternative possible answer to the enigma confronted in the first paragraph. The only required thing in order to conceive a semiotic process that involves no representation ${ }^{4}$, would be to

3 References to the Collected Papers of Charles S. Peirce are shown by " $\mathrm{CP}^{\prime}$ followed by volume and paragraph (not page) number. References to The Essential Peirce are shown by "EP" followed by volume and page number.

4 Strictly speaking, the process of unlimited semiosis seen as a "dialogue" (Nöth, p. 43) can only be interrupted and never really ended. In the case of rhythm, I will argue, the process is not interrupted but invaginated or looped in a way that represents a kind of semiotic cul de sac-in the sense that restarting the semiosis process does not work as a continuation of a rhytmical semiotic process. In this sense, rhythm is a solution of continuity within the realm of unlimited semiosis. 
close the apparently infinite game of likenesses by reducing icons to refer to themselves over and over. That can be done by creating a recurrence of likeness ${ }^{5}$.

If we are in a world where $A$ is like $B$, but then B is like A, we can produce a cycle of likenesses that tend to repeats itself, so eliminating further reference to a third party. This is the core of the idea of rhythm discussed here: the creation of a world of perceptions that directs icons toward themselves, suspending external reference and stopping -or better said, enclosing- the process of infinite semiosis

Inside the cycles of rhythm, icons temporarily loose their openness to the external world. ${ }^{6}$ I have to briefly mention here the issue of perceptual judgement as different from the interpretant of a cognitive sign. As Peirce puts it, commenting on Aristotle's 'Nihil est in intellectu quod non prius fuerit in sensu': "As for the other term, in sensu, that I take in the sense of in a perceptual judgement, the starting point of first premiss of all critical and controlled thinking." (CP 5,181). In rhythm, now, we can say that a "meaning as a relational pattern" (Rosenthal, p. 28) emphazises the end of "sensuous recognition" in a continuous that has, on the other end, conceptual interpretation. In rhythm, icons act like chemical elements that become unable of new combinations, suspending the conceptual completion of the interpretant. More precisely, they can combine once and again, and only in the same way, with the same partner. Regardless of how complex a particular rhythm may be, it is a closed entity, which tame its icons and forces them to refer to themselves. Rhythm is iconic self reference.

\section{The suspension of intellectual interpretation}

By reducing iconic freedom, rhythms don't affirm, nor deny. We can make an interpretation of a rhythm, of course, in the sense that our con-

5 This opens the possibility of contrasting rhythm with metaphor, understanding that in rhythm likeness does not play the role of connecting symbols with other iconic components apart from the rhythmic iconical core that is operating in any rhythm, while in metaphor icons work always in connection with "something else" that opens in the symbolic dimension of the interpretant. For a discussion of the cognitive dimension of metaphor in Peirce, see Sorensen, 2006, and especially 2007.

6 Strictly speaking, the process of unlimited semiosis seen as a "dialogue" (Nöth, p. 43) can only be interrupted and never really ended. In the case of rhythm, I will argue, the process is not interrupted but invaginated or looped in a way that represents a kind of semiotic cul de sac-in the sense that restarting the semiosis process does not work as a continuation of a rhytmical semiotic process. In this sense, rhythm is a solution of continuity within the realm of unlimited semiosis. 
ceptual ability allows us to do so. But while any object or experience in the world is open to likeness, it drives us -due to our talent for likeness and our past experiences- to this or that particular interpretation. Not only words and speech, any conventional sign is bound to be meaningful. We feel that even a color in a flag, a smell in the air, automatically 'mean' something to us. In the case of rhythm, that 'meaning' quickly disappears. We are driven to the feeling of repetition, and repetition plays a key role in Peirce's notion of regularity. Repetition emphazises the work of patterns in the building of our being in the world, in contradistinction with chaos (Chiasson, p. 139 ss.); and we do not look for an explanation whenever we find a regularity (CP 7,194). The regular character of rhythm does not call for intellectual wondering, despite its regular character, precisely because it does not offer anything but the icon of repetition, offering the stimmung (Gumbrecht, p. 3 ss.) of regularity whithout the motivation to search for intellectual explanations behind it. We tend to grasp a particular rhythm as one and only one thing. We are directed towardss unity by the multiplicity of self-references that rhythm sets up.

In that operation, icons lose their peculiarities in every other respect, and begin to refer only to their counterparts inside the rhythmic pattern. If a drummer is playing, every beat of the bass drum becomes an icon of every other bass drum beat, every hi-hat tells us of the next and past hi-hat beats, and so forth. Of course, our drummer creates a rhythm that can be very rich and complex, and each component of the pattern get related with every other component. But what constitute a rhythm out of a set of beats are the self-referred iconical relationships set up by the repetition. A particular snare or cymbal has, of course, a very distinct and complex richness of sound. In itself, it can be interpreted as an icon of this or that object of the universe. For instance, we can feel that some quality in the sound of the cymbal resembles to us the quality of the sound of a waterfall. But, when that particular quality of sound enters in a rhythmic pattern that causes the mutual reference of one cymbal beat with another cymbal beat, the strong link created by the repetition limits any further reference of the cymbal to the fall. Rhythm imposes itself as a total experience which has no meaning. We can intellectually try to evade ourselves of this imposing meaningless, and assign an interpretation to it, but we cannot avoid the presence of rhythm beside our interpretation. Rhythm is a centripetal phenomenon that attracts mind to its perfect muteness. 
Josiah Royce (1903) has reminded us about this peculiar ability of rhythm to force their components to 'refer' to rhythm itself:

If one listens to any simple rhythm, such as the ticking of a watch, one can note how the succession of separate ticks is viewed by our consciousness in such a way that the successive beats do not stand as merely separate facts, but are always elements in the whole experienced rhythm to which they seem to belong, while the successive presentations of the rhythm form a sort of stream of events, each one of which gradually dies out of mind as the new event occurs. In consciousness there is no such thing as an indivisible present moment. (p. 83).

By canceling the iconical power of intellectual association, rhythm has a very peculiar side effect: it suspends our intellectual interpretation habits. Of course, a widened -semiotical- notion of interpretation shows that any semiotic event necessary involve all three classical dimensions: Thirdness, Secondness, Firstness. In Peircean terms, any reaction we experience in our minds or even in our bodies, to the extent that is a general category, is an interpretant. So of course we can say that our body movements when we react to a musical rhythm are our 'interpretation' of it. And of course, body movements called 'dance', clearly are a culturally defined interpretation. Movements of this or that dance -from tango to salsa, from waltz to rap- are kinds of 'words' of a body language, and a more or less culturally defined general category. But they are interpretants made out of a kind of world substance, and not of meaning, and their interpretations don't change rhythm. We know that they are not part of a game of intellectual likenesses. With this theoretical arsenal of semiotics applied to rhythm, at a first step we can consistently tell between intellectual interpretation and non-intellectual 'interpretation' -or the direct presence and action of the perceptual judgement-. The next step would be more like a metaphor build over the first.

\section{Rhythm and Index}

The iconic and the symbolic fill the representational part of the semiotic game, while the indexical is related with direct reference, with presence, with inertia and with the substance, with action of "brute force" $(E P 2,5)$. In the process of loosing its iconic and symbolic power because of iconic self-reference, the elements of rhythm concentrate themselves 
in their indexical direct essence. As parts of rhythm, they are for us nothing more than 'elements that focusses our attention': "Anything which focusses the attention is an index. Anything which startles us is an index, in so far as it marks the junction between two portions of experience." (CP 2,285)

Each and every element composing a rhythm of any kind, makes itself present in our world as a direct presence, as an index of the rhythm as a whole. Each beat is a symptom of the only rhythm, as a leaf is a symptom of the organic presence of a tree.

When we attempt to represent it, rhythm shows has that it has also the peculiarity of being a resilient self-representative entity. There are no symbols of rhythm, except for another rhythm. We can paint a dance by repeating visual figures. We can only write music producing a repetition of visual marks -a visual rhythm- in a paper. We can only represent the rhythm of heavenly planets by a rhythmical cycle of numbers, or by a circular diagram that leads us to visual repetition.

\section{Some conditions of rhythm}

Anything can act as a sign of something. The legitimacy of that fact depends on the grounds on which we produce our interpretation.

But from the last sentences it doesn't follow that anything is actually a sign. In fact, anything which may present some distinct feature to our senses is a candidate to convert itself in a sign of another sign/object at a very fast pace. Visual objects of any kind, for instance, are quickly recognized 'as' this thing or another, and in that respect, they get immediately integrated in some train of interpretations or another.

Rhythm is a very different and peculiar entity. Rhythm can assume functions of representation, but it is not necessarily a sign of another object or entity. Rhythm is a self-referent entity, perhaps the self referent entity. It is build over self reference, and its life is marked by the beginning and the end of its being self-referential. When rhythm looses its self-referential condition, it is no more a rhythm, and instantaneously comes to an end.

I am not referring here only to rhythms perceived with ears, but to any kind of rhythms. Visual rhythms, like the succession of bars and air 
in a railing; rhythms perceived by touch, body and equilibrium, like the ones we feel when we are dancing or consciously breathing; rhythms perceived by taste or smell, like the consecutive sensations when we are chewing or drinking at regular intervals. All of them have in common that create a form of experience that is non-representational. The axis of our being there is translated from the centrifugal tendencies of interpretation, to the centripetal ones of focalization. We are now prepared to list some conditions of rhythm:

1) Two different elements composing a particular rhythm must have the ability of manifest themselves as icons of each other. That capacity does not mean that each and every element of a rhythm should necessary be an icon of all other element composing the same rhythm. But each element of a rhythm must be the icon for at least another element of the same rhythm.

2) All elements composing a particular rhythm close their iconical openness to the 'external world' due their redirection toward other instances of themselves within a rhythmical sequence.

3) Any rhythm which is perceived during some time will cause a change in perception of rhythm, because of the self-referential character of that particular perception. Perception of rhythm tends to become unconscious due to the 'anesthetic effect' that repetition has over senses. But since the perceiver can only perceive himself in his perceptions, the perception of rhythm has also the ability of changing the self perception of the perceiver.

4) All this phenomena involved with rhythms are not a matter of interpretation. They don't represent anything at all. The reason why they don't represent anything is because icons present in each and every element composing the perceived rhythm, as the natural vehicles of any representation, tend to act themselves as icons of other elements inside the same rhythm, creating an 'opposite mirrors' effect that closes the attempt of refer icons to external objects different than the similar elements inside the same rhythm.

5) All rhythm is an icon of any other rhythm.

6) All representation of rhythm must be iconically rhythmical. 


\section{Brief concluding observations on a non- Hermeneutic dimension of rhythm}

Meaning in general -and so, any interpretation of the concept of rhythm- has been conceived as an intellectual -and specifically non-material- object, since the first paragraph of Aristotle's 'Peri Hermeneias'. The understanding of meaning as a pure intellectual and 'spiritual' problem prevails equally in the all-strong twentieth-century traditions of French sémiologie and German Hermeneutik. In order to perceive the self-referential dimension that constitutes a very distinctive feature of any experience of rhythm, it will be required to first pay attention to one peculiar aspect of any experience of rhythm: rhythm presents itself to mind as an intriguing entity. Therefore, our implicit question over this piece has been: why is the philosophical -i.e. object of general and abstract reflection- entity of rhythm a mysterious one? What is it that makes 'rhythm' as a phenomenon, something so difficult to grasp, and to explain in words? Not to mention the extremely evasive nature of its function in relation to meaning.

Rhythm can be traced as something alien to meaning and semantics that, nevertheless, can be recognized as such alien in words and concepts, inside our customary games of meaning. It is normally felt as something present to mind/ body, but not translatable to language -as part of the 'world' in its broadest sense, but not as part of 'our world' in the hermeneutic sense-. Perhaps, one can say, rhythm is part of the world, but it is not capable of playing any significant part in our intellectual 'world', since our intellectual tradition is for our knowledge the pre-condition that filters out any non-intellectual reality.

By no means could that inclusion be just 'hermeneutic', in the sense that rhythm cannot appear as a semantically characterized part of meaning. Gumbrecht uses F. Maturana's notion of consensual zone of first order to propose a way of conceptualizing why rhythm does not appear at our 'hermeneutic' level of understanding: "If what we call rhythm appears primarily in consensual zones of the first order [...] then rhythm does not command a level of semantic description, and the organisms coupled via rhythm do not produce the status of observers" (1994, p. 180).

Through this strange but highly suggestive approach, we can acknowledge that rhythm occurs in a different realm than that within 
which we recognize meanings. Our mind cannot help but try to go 'back' and catch, always with delay, 'rhythm', something that is obscurely felt, but that is not understood.

So we are in the position of retrieving rhythm through rhythm's footprints in meaning, like detectives. We have no hope of catching live rhythm at all inside the field of conceptual discourse. Nevertheless, we should attempt to provide a reliable proof and testimony of its presence.

The nature of such operation is twofold. On the one side, it should attempt the architectural task of grounding itself in epistemic terms. On the other, it should describe how rhythm is a presence in a world of meaning, without being anything of meaning in itself.

In what has been written here, there is the suggestion that some central ideas and categories proposed in Charles Sanders Peirce's philosophy can be useful for an accounting of rhythm inside the Humanities ${ }^{7}$. One of the crucial points of difference between semiological and peircean approachs -i.e., the quarrel on the place of 'natural languages' inside communication and thought at large-, has been eventually terminated with the assumptions made by Benveniste and Gadamer about the absolute primacy of verbal languages over 'other semiotic systems', which are considered either as more primitive 'languages', or as derivative and secondary ones.

I believe that such an assumption can only be made if we choose to reduce the (according to Peirce) three phenomenological levels of existence, to just the third one, i.e. the level of habit, and of conventional meaning -in Peircean terms, 'Thirdness'-. Reversely, if we admit that there are another two levels which should necessarily exist in any phenomenological approach to the world, we can understand how rhythm is part of them without being properly translatable, without a substantial lost, to the level of Thirdness, or 'meaning'.

7 The strategy of discussing rhythm from the point of view of scientific theories -from, for instance, biology- is a very interesting task also. The kind of epistemological mixings which can be developed from that perspective could illuminate new ways of interrelation between humanities and sciences. 
From what I have stated we can infer tha ${ }^{8} t$ the operation of grounding our knowledge of our world only in concepts -and not in processes composed of many levels-is the very beginning of our problem ${ }^{9}$. I addressed that issue through a brief analysis of at least two non-conceptual levels involved in the phenomenon of rhythm.

8 Except in case some particular rhythm has acquired, by repetition, some particular meaning to us. For instance, when a piece of music is well known to us and we recognize it when hearing its rhythmic introduction, or when the chimes of our car make a particular rhythm "meaning" we have to fasten our seat belts.

9 The metaphor I would suggest for this maneuver is that of a phenomenological millefeuille, which one cannot help but eating without consciously analyzing it... What I suggest is that rhythm is a necessary part of that cake -let us say, the jam and cream of it-. We, of course, can only 'understand' that through a non-syncronized work of meaning -let us say, we can eventually arrive to a final concept such as 'I am eating a cake'-. The latter assumption is, of course, tautological, but one cannot help to repeat tautologies in order to suggest rhythm. 


\section{Works Cited}

Aristotle. (1995). Poetics. Translated by Stephen Halliwell. Loeb Classical Library.

Chiasson, Phyllis. (2001). Peirce's Pragmatism: The Design for Thinking. Atlanta, GA: Rodopi.

Gumbrecht, Hans Ulrich. (2012). Atmosphere, Mood, Stimmung. On a Hidden Potential of Literature. Stanford: Stanford UP.

. (1994). "Rhythm and Meaning". In H. U. Gumbrecht and K. L.

Pfeiffer (Eds.) Materialities of Communication. Stanford, CA: Stanford University Press.

Nöth, Winfried. (1990). Handbook of Semiotics. Bloomington, IN: Indiana University Press.

Peirce, Charles S. Collected Papers, volume 1-6, ed. Hartshorne, C. \& Weiss, P.; volume 7-8, ed. Burks, A W., Cambridge Mass.: Harvard University Press, 1958.

(1992). The Essential Peirce. Selected Philosophical Writings. Volume 2. Peirce Edition Project (Ed.). Bloomington: Indiana University Press.

Rosenthal, Sandra, B. (1994). Charles Peirce's Pragmatic Pluralism. Albany: State University of New York Press.

Royce, Josiah. (1903). Outlines of Psychology. London: MacMillan.

Sørensen, Bent \& Torkild Thellefsen (2006): "Metaphor, Concept Formation, and Esthetic Semeiosis in a Peircean Perspective". Semiotica 161-1/4 (Special Issue on Metaphor, Guest ed. Nuessel, F.). Berlin/New York: Mouton de Gruyter, 199-213.

Sorensen, Bent, Torkild Thellefsen, Morten Moth. "Metaphor and Cognition from a Peircean Perspective". Transactions Of The Charles S. Peirce Society Vol. 43, No. 3 @2007

Rosenthal, Sandra, B. Charles Peirce's Pragmatic Pluralism. Albany: State University of New York Press, 1994. 